\title{
Catastrophic Times and Feminist Histories
}

\author{
Kate Davison and Alexandra Ciaffaglione
}

This new decade began in a baptism of fire with environmental catastrophes in Australia, the Brazilian Amazon and on the west coast of the United States. Political crises took a foothold in global news and became a clarion call for institutional and societal change, as they demonstrated the inherent and devastating nature of white supremacy, white privilege and the continual impact of colonisation. The COVID-19 pandemic, which has caused the loss of millions of lives worldwide, has exposed systemic problems that have previously been ignored or deliberately obscured. The past year and a half has irrevocably transformed how we experience life and how we understand our place in it.

Survival, resilience and how we respond as a global society in the face of such catastrophe are running themes woven throughout this issue. In the creation and organisation of this issue, our central question has been what does 'feminist history' signify in catastrophic times? The events of the past year and a half have generated renewed interest in the social, political and even academic conceptions of feminism, gender and equality. Revelations of sexual harassment and assault within the Commonwealth Parliament have emerged as part of renewed public attention to the treatment of women, not only in politics but in workplaces more generally. The Sex Discrimination Act 1984 was a major achievement for feminism in Australia, yet recent times have exposed just how little the spirit of the Act has been imbibed by the country's governing institutions; rather, those governing institutions are still working actively against it. We are now confronted with its gaps and shortcomings as well as its silences. The response by Parliament and the government to the revelations shows how much women are pushed to the side, their issues perceived as nonissues, their perspectives ignored, their voices silenced. These processes are all the more aggressive and pernicious in the realms of society beyond the purportedly rules-based political infrastructure of Canberra. This is especially the case in terms of policing and the colonial oppression of Indigenous women in this country. Racism, workplace discrimination, 
unequal pay, the continued - often violent — enforcement of the gender binary, homophobia and widespread gender-based intimate partner violence can be interpreted as ongoing catastrophes in their own way.

If revealing the history of these structural catastrophes is a core duty of feminist historiography, it is made all the more difficult by the federal government's ongoing de-funding of national cultural institutions such as the National Archives of Australia (NAA). Our cover image for this issue is taken from the NAA collection, a crucial repository for the history of feminist struggle in Australia, but also a place where we find evidence and source material revealing the colonial legacies of this country. As Michelle Arrow pointed out in The Conversation (27 April 2021), the impending destruction of audio and video material in the NAA collection will be disastrous for historical understandings of the Australian past-it was this kind of material that enabled the important feminist history documentary Brazen Hussies (Catherine Dwyer, 2020) to be made. The same problem can be found in other national cultural repositories such as the National Library of Australia, where budget and staff cuts have threatened vital services such as the Trove catalogue tool and the digitisation of collection material.

How can feminist history respond to such restrictions and curtailments? In the universities, efforts to preserve and even advance this and related fields have seen some successes. The Department of Indigenous Studies at Macquarie University, for example, is providing dedicated institutional space to gender and sexuality within Indigenous Studies through a new Indigenous Queer Identities and Cultures stream led by non-binary scholar Professor Sandy O'Sullivan (Wiradjuri). Elsewhere, however, piecemeal trends in gender history continue, with offers of fractional, parttime and short fixed-term jobs. It is questionable whether such precarious offers really do feminist history any good, let alone their impact on the earning potential and career prospects of their (disproportionately female) incumbents. If anything, such developments may only serve to perpetuate age-old structural disadvantages for both women in the profession and feminist history overall, reflecting broader glass ceilings in research funding and grants, and publishing practices as well. These have only been exacerbated during the COVID-19 pandemic.

The seven contributions to this issue articulate experiences of women in the past that can shed light on the present-day issues explored above. Questioning feminism, grasping or asserting power and resisting silence 
are the threads weaving this issue together. Jacquelyn Baker explores the tension between heterosexual and lesbian women in 'The Lavender Menace Comes to Melbourne: Feminism, Lesbianism, Place and Space in the 1970s', with an examination of the Women's Liberation movement in Australia and the concept of safe space. Linda Wells advances scholarly exploration of decolonising history, colonial silence and the structures of power to bring alive the voices of the women and children in 'The Story of the Bungalow Alice Springs, 1914-1929: A Decolonised, Creative Non-Fictive Treatment with a Focus on the Women and Children'. Two articles focus more on non-public spheres. Exploring gendered practices of knowledge sharing in "Wright By Her Own Hand": Recipe Exchange and Women's Kinship Networks in Ascendancy Ireland, 1690-1800', Madeline Shanahan depicts the ways in which women have utilised agency in the formation of kinship networks spanning several generations. Danielle Scrimshaw takes a biographical approach by piecing together a portrait of Katie Anna Lush (1887-1935), a University of Melbourne lecturer in literature and the muse of the poet Lesbia Harford in "Lovely and Secret": The Life of a Poet's Muse, Katie Anna Lush'. Through Lush's biography, Scrimshaw offers insight into the lives of white unmarried women within the academic and political spheres of early twentieth-century Melbourne, as well as reading the relationship between Lush and Harford through a queer lens. Moving back into the public sphere, in 'Spectacle and Political Gimmicks: The Women's Crusade for Liberty, 19471949', Wendy Michaels investigates how public spectacle and theatrical gimmickry was used as a mechanism of individual and collective agency by the conservative Australian Women's Movement Against Socialism (AWMAS). In "Your Life is More Pleasant with Wine": Australian Wine Board Advertising in the Australian Women's Weekly, 1955-1965', Alison Vincent analyses how the Australian Wine Board conducted a targeted campaign towards women in a tacit acknowledgement of their ability to influence and institute change in the culture of wine consumption within the home. Sharyn Clarke explores women's role in popular science and the processes of power within the patriarchal natural history establishment of the late nineteenth and early twentieth centuries in 'Women, Popular Science and Recreation: The First 25 Years of the South Australian Field Naturalists'. 
This text is taken from Lilith: A Feminist History Journal: Number 27, published 2021 by ANU Press, The Australian National University,

Canberra, Australia.

doi.org/10.22459/LFHJ.27.00 